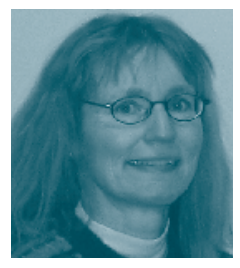

Anne Torine Litherland uroterapeut/sykepleier.

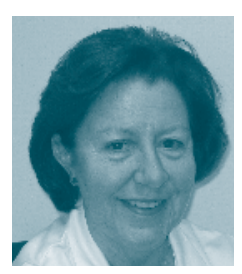

Astrid Gjersøe, avdelingsleder da prosjektet ble gjennomført.

Begge skribentene jobber på poliklinikk for kvinnesykdommer ved Sykehuset i Vestfold. www.sykepleien.no

Les mer og finn litteraturhenvisninger på våre nettsider.

Søkeord: ) Urologi

) Urinveier

) Poliklinikk

\title{
Gir hjelp ved
}

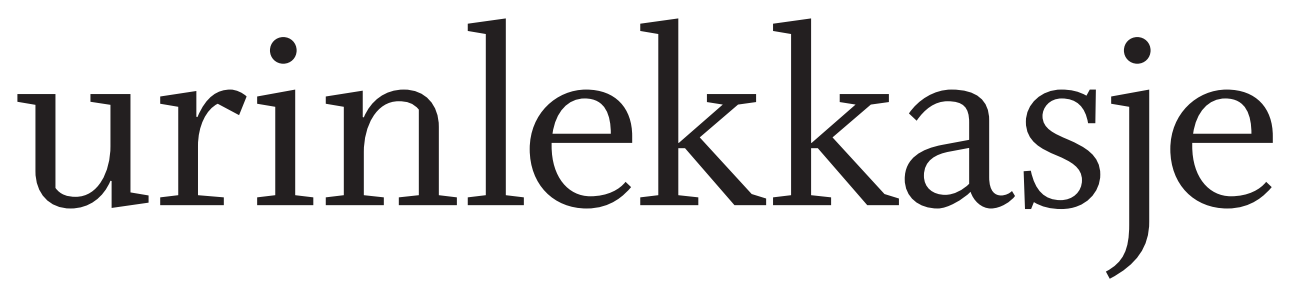

\author{
Uroterapeuten har en viktig rolle i utredning og behandling av kvinner \\ med vannlatingsproblemer.
}

$\mathbf{U}$ rinlekkasje er et problem som rammer mange kvinner (1). Det er et kostbart problem både samfunnsøkonomisk og for den enkelte. Tilbudet til disse pasientene varierer fra sted til sted i Norge. Ved noen sykehus har uroterapeuter overtatt deler av utredningen og behandlingen av denne pasientgruppen $(2,3)$. De fleste uroterapeuter er sykepleiere som har tatt videreutdanning innen funksjon og dysfunksjon i de nedre urinveier. En studie fra Australia viser at kvinner med inkontinens som ble behandlet av sykepleiere med spesialisering innen inkontinens fikk økt livskvalitet (4).

\section{Pasientundersøkelse}

Ved poliklinikk for kvinnesykdommer, Sykehuset i Vestfold, har vi siden år 2000 hatt to uroterapeuter i halv stilling. I løpet av denne perioden har vi gradvis utviklet et system for å ta oss av disse pasientene. Vi ønsket å evaluere dette systemet og å se på hvilket arbeid uroterapeutene ved vår poliklinikk gjør. En annet aspekt vi ønsket å vurdere, var hvor stor andel av pasientene som var fornøyd og oppnådde tilfredsstillende bedring etter utredning og oppfølging hos uroterapeut, det vil si uten konsultasjon hos lege. Vi har derfor gått gjennom journalene til alle pasientene som var til første konsultasjon hos uroterapeut i kalenderåret 2005.

\section{Kliniske rutiner}

De fleste kvinner i Vestfold med vannlatingsbesvær blir henvist til Urogynekologisk seksjon ved poliklinikk for kvinnesykdommer. Seksjonsoverlegen vurderer alle henvisningene. Flertallet av pasientene blir satt opp til primær utredning hos uroterapeut. Pasienter som har mer kompliserte tilstander, får time til full urodynamisk undersøkelse, eventuelt en første vurdering hos spesialist i gynekologi. Urodynamisk undersøkelse utføres av lege og uroterapeut i samarbeid.

Før utredningstimen får pasienten tilsendt et validert, strukturert spørreskjema og en 24-timers miksjonsliste med bleieveietest. Dette kan gi oss en viss informasjon om antall miksjoner og volum fordelt gjennom et døgn (5). Vi setter av 60 minutter til utredningen.
Uroterapeut og pasient går først gjennom papirene pasienten har fylt ut hjemme. Den kliniske undersøkelsen begynner med urinflow-måling. Deretter sjekker vi vaginal knipeevne ved palpasjon i skjeden. Vi måler resturin med kateter, og gjennom det samme kateteret fylles blæren med $300 \mathrm{ml}$ sterilt saltvann. Enkelte pasienter med urge-inkontinens får blærekontraksjon i forbindelse med fylling, hvilket bekrefter denne diagnosen. Når pasienten hoster kan vi se om det er hostesynkron lekkasje (det vil si stressinkontinens). Til slutt utføres en standardisert stresstest med 20 splitthopp og tre host med $300 \mathrm{ml}$ i blæren og registrering av lekkasjemengde (6).

\section{Behandling}

Etter undersøkelsen blir pasienten informert om hva undersøkelsen har avdekket og hva som kan være årsaken til problemene. Kvinnen får råd om drikke- og toalettvaner, informasjon om lekkasjetyper og behandlingsalternativer. Det blir tatt stilling til videre opplegg og behandling.

\section{Mange av kvinnene har dårlig funksjon i bekken- bunnsmuskulaturen.}

Mange av kvinnene har dårlig funksjon i bekkenbunnsmuskulaturen. Forskning viser at bekkenbunnstrening er effektiv behandling for anstrengelseslekkasje (7), og de som har svak bekkenbunn bør forsøke en periode med intensiv bekkenbunnstrening. Avhengig av den enkelte pasients ønske, gir vi henvisning til fysioterapeut, eller vi bestiller et biofeedbackapparat. Det viktigste er at pasienten finner en treningsform som passer for henne. Bekkenbunnstrening med biofeedback betyr at pasienten ved hjelp av et apparat med en probe i skjeden, får tilbakemelding om hvor hardt hun kniper. Disse apparatene kan pasienten låne og bruke hjemme. Enkelte kvinner som strever 
med å knipe riktig kan ha nytte av elektrostimulering en periode for å «vekke» muskulaturen.

Ved overaktiv blære anbefaler vi elektrostimuleringsbehandling, vanligvis i skjeden $(7,8)$. Behandlingen gjøres hjemme, og stimuleringen tar 15-20 minutter tre til sju ganger i uken.

\section{Råd og veiledning}

Blæretrening brukes også til behandling av overaktiv blære (9). Vi har ikke fulgt et fast opplegg for blæretrening, og derfor er denne behandlingsformen ikke registrert i vår undersøkelse, men flertallet av våre pasienter med symptomer på overaktiv blære får enkle råd om å utsette vannlatingen og får utdelt en

\section{Mange pasienter med urinlekkasje må bruke beskyttelse i form av bind eller bleier.}

brosjyre om blæretrening. Postmenopausale kvinner vil ofte ha nytte av tilskudd av østrogen lokalt (10).

Mange pasienter med urinlekkasje må bruke beskyttelse i form av bind eller bleier. Det er viktig å gi dem informasjon om de forskjellige typene som finnes på markedet. For noen kvinner med anstrengelseslekkasje vil vaginale støtter være et godt hjelpemiddel (11). Kvinner som har residiverende urinveisinfeksjon, får råd og anbefalinger om behandling og forebygging. Alle som starter med konservativ behandling, får kontrolltime hos uroterapeut etter behov. Sitat.

Ved anstrengelseslekkasje av moderat

eller stor grad får pasienten time hos gynekolog til operasjonsvurdering. Noen av pasientene med lett grad av lekkasje ønsker også vurdering hos gynekolog, og får det. Ved uklare tilstander blir pasienten vanligvis tilbudt urodynamisk utredning. Hvis uroterapeuten $\mathrm{i}$ løpet av undersøkelsen oppdager andre tilstander, får pasienten time hos gynekolog.

\section{Materiale og metode}

Studien er godkjent av Regional komité for medisinsk forskningsetikk og Norsk samfunnsvitenskapelig datatjeneste AS. I 2005 hadde 214 kvinner første konsultasjon hos uroterapeut ved vår poliklinikk. I denne studien har vi gått gjennom de 214 journalene. Vi registrerte henvisningsinstans, dato for henvisning og første time, henvisningsdiagnose, hva pasienten beskrev, hva undersøkelsen avdekket og hva som ble bestemt videre. Vi registrerte også antall konsultasjoner og hva som ble gjort hos uroterapeut, hvor mange pasienter som gikk videre til gynekolog og eventuelt kirurgisk behandling.

Informasjonen ble registrert på et eget skjema utarbeidet for formålet og lagt inn i dataprogrammet SPSS for analyse.

\section{Resultater}

Kvinnenes medianalder var 53,3 år (28-89). 105 (49 prosent) var henvist fra allmennlege, 86 (40 prosent) fra privatpraktiserende gynekolog, 14 (7 prosent) fra kvinnepoliklinikken og 7 (3 prosent) fra andre poliklinikker ved sykehuset. Én pasient var selvhenvist
Figur 1. Behandlingstiltak igangsatt av uroterapeut

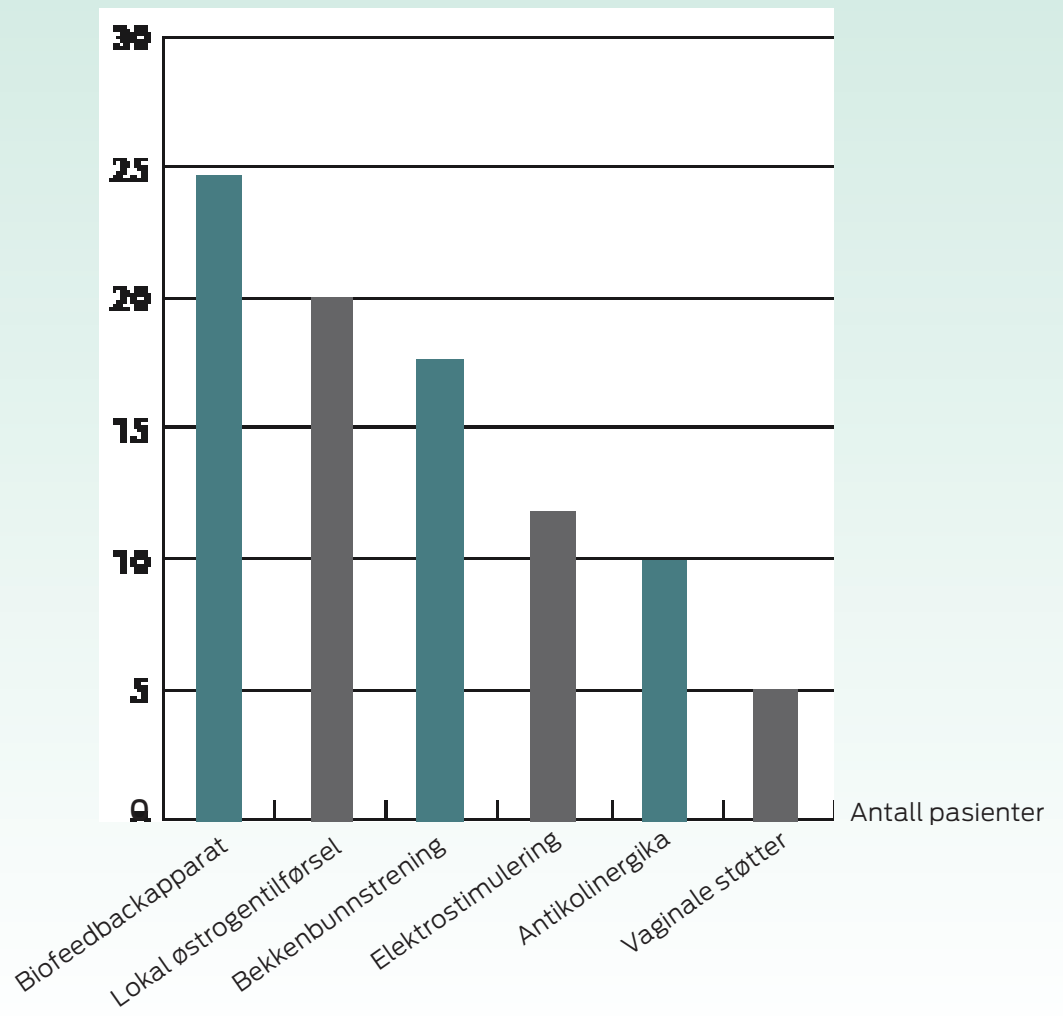

og for én pasient var henvisningsinstansen ukjent. Den vanligste henvisningsdiagnosen var stressinkontinens (73 prosent). Median ventetid før første konsultasjon var 44 dager (6-279).

Utredningene avdekket 149 (70 prosent) tilfeller av anstrengelseslekkasje, 58 (29 prosent) pasienter hadde svak bekkenbunnsmuskulatur. 31 (14 prosent) hadde urgeinkontinens, og ti (5 prosent) av pasientene hadde et høyt væskeinntak. Resturin ble påvist hos ni (4 prosent) og hos åtte (4 prosent) pasienter ble det funnet descens (fremfall). Hos 15 (7 prosent) av pasientene ble det ikke påvist noe spesielt.

Alle behandlingstiltak som ble igangsatt av uroterapeut er vist i figur 1. Mange pasienter startet flere tiltak samtidig. Totalt 60 (28 prosent) av pasientene hadde ikke behov for ytterligere tiltak etter konservativ behandling og oppfølging hos uroterapeut.

16 (7 prosent) av pasientene var fornøyde med informasjonen og rådene de fikk ved utredningstimen og trengte ikke videre oppfølging. 20 pasienter ble anbefalt å begynne med vaginal østrogentilførsel (reseptfritt). 150 pasienter (69 prosent) fikk time hos gynekolog til vurdering for kirurgisk behandling av anstrengelseslekkasje.

\section{Diskusjon}

Konklusjonen i artikkelen «Systematic review and metaanalysis of methods of diagnostic assessment of urinary incontinence» (12) er at det kan stilles riktig diagnose hos en stor andel av kvinner med urinlekkasje på bakgrunn av sykehistorien. Ved å legge til miksjonsliste, bleieveietest og stresstest får vi et enda bedre grunnlag for å vurdere pasientens urinveisfunksjon (6). 


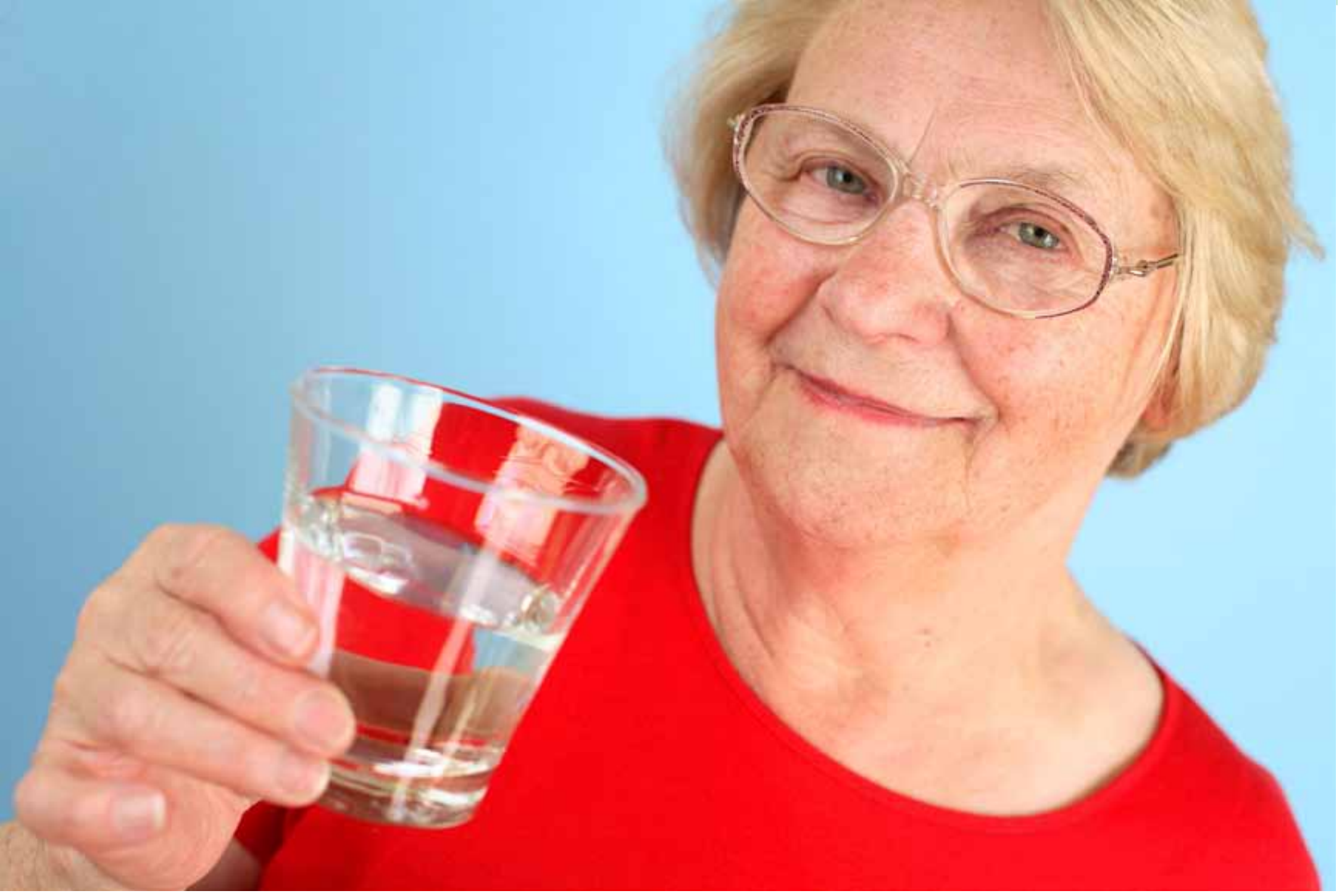

ENKEL BEHANDLING: Kvinner med urinveis

problemer får råd av urolog om drikke- og toalettvaner, informasjon om lekkasjetyper og behandlingsalternativer. Illustrasjonsfoto: Colourbox

Hos oss er det uroterapeuten som selekterer de pasientene som skal videre til gynekolog. Mens ved spesialistpoliklinikker får alle pasientene time hos gynekolog uansett hva utredningen hos uroterapeut har avdekket (3). På denne måten unngår vi at pasienter får legetime som de ikke trenger, og pasientflyten blir god.

Mange av pasientene i vår undersøkelse uttrykte lettelse over å komme til en kvinne, når det gjaldt disse problemene. Da undersøkelsen ble utført, var det kun mannlige urogynekologer ved vår avdeling. Uroterapeutene erfarer at god tid til hver pasient gjør at pasientene opplever at de blir møtt, hørt og tatt på alvor med sine problemer.

\section{Hos sju prosent av pasientene var kun én time hos uroterapeut tilstrekkelig.}

Forbausende mange postmenopausale kvinner har ikke fått råd av henvisende lege om å begynne med lokal østrogenbehandling når de har urinveisproblemer.

\section{Få trengte lege}

Konservativ behandling og oppfølging hos uroterapeut ga gode

\section{LITTERATUR}

Hannestad YS, Rørtveit G, Sandvik H, Hunskår S. A community-based epidemiological survey of female urinary incontinence: the Norwegian EPINCONT study. J Clin Epidemiol 2000; 53: 1150-7.

2. Ytrehus $Y$. Utredning og behandling av kvinner med lekkasjeplager. Sykepleien 1996; 11:50-3.

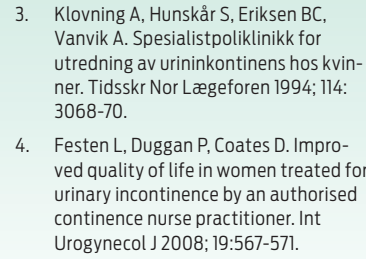
Vanvik A. Spesialistpoliklinikk for utredning av urininkontinens hos kvinner. Tidsskr Nor Lægeforen 1994; 114 : 3068-70.

4. Festen L, Duggan P, Coates D. Improved quality of life in women treated fo urinary incontinence by an authorised continence nurse practitioner. In Urogynecol J 2008; 19:567-571.

5. Kulseng-Hanssen S, Borstad E. The development of a questionnaire to measure the severity of symptoms and the quality of life before and after surgery for stress incontinence. BJOG 2003; 110: 983-8.

6. Kulseng-Hanssen $\mathrm{S}$. The development of a national database of the results of surgery for urinary incontinence in women. BJOG 2003; 110: 975-82.
7. Schiøtz HA. Stressinkontinens hos kvinner - aktuell behandling. Tidsskr Nor Legeforen 2007; 127: 1773-6.

8. Indrekvam S. Elektrostimulering ved urininkontinens hos kvinner. Tidsskr Nor Lægeforen 2003; 123: 55.

9. Hunskår S, Vanvik A, Eriksen BC. Blæretrening ved urininkontinens hos kvinner. Tidsskr Nor Lægeforen 199]; 111:3298-9.
10. Norsk elektronisk legehåndbok

11. Dahlstrøm BL. Tamponger - et hjelpemiddel ved stressinkontinens? Tidssk Nor Lægeforen 1995; 115: 365-6.

12. Martin JL, Williams KS, Sutton AJ, Abrams KR, Assassa RP. Systematic review and metaanalyses of methods of diagnostic assessment for urinary incontinence. Neurourol Urodyn 2006 